\title{
FATTY ACID PROFILE OF NON-CONFORMING POOLED HUMAN MILK AS AFFECTED BY THE PROCESSING AND STORAGE CONDITIONS
}

Otávio A. S. Ribeiro *1, 2 (iD), Kely P. Correa 1, Mauricio O. Leite ${ }^{3}$ iD, Marcio A. Martins $^{3}$, Jane S. R. Coimbra ${ }^{1}$ iD

${ }^{1}$ Departamento de Tecnologia de Alimentos, Universidade Federal de Viçosa (UFV), Av. P.H. Rolfs,

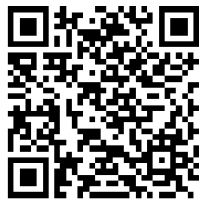
s/n, 36570-900. Viçosa, MG, Brazil

2 Centro Multidisciplinar, Universidade Federal do Acre (UFAC), Estrada do Canela Fina, Km 12, Gleba do Formoso, 69980-000. Cruzeiro do Sul, Ac, Brazil

${ }^{3}$ Departamento de Engenharia Agrícola, Universidade Federal de Viçosa (UFV), Av. P.H. Rolfs, s/n, 36570-900. Viçosa, MG, Brazil

DOI: https://doi.org/10.29121/granthaalayah.v9.i2.2021.3276

Article Type: Research Article

Article Citation: Otávio A. S. Ribeiro, Kely P. Correa, Mauricio O. Leite, Marcio A. Martins, and Jane S. R. Coimbra. (2021). FATTY ACID PROFILE OF NON-CONFORMING POOLED HUMAN MILK AS AFFECTED BY THE PROCESSING AND STORAGE CONDITIONS. International Journal of Research GRANTHAALAYAH, 9(2), 46-54. https://doi.org/10.29121/granthaa layah.v9.i2.2021.3276

Received Date: 24 January 2021

Accepted Date: 19 February 2021

Keywords:

Gas Chromatography

Lipids

Nutrition

Preterm

Storage

\section{ABSTRACT}

The fatty acid's contents of non-conform pooled human milk can be affected by different processing and storage operational conditions. Besides, the knowledge of changes in the human milk fatty acid profile can help indicate its use in a given storage period, according to each newborn's specific need. Thus, in the present work, changes in the fatty acid profiles of three types of human milk (raw; pasteurized at $62.5{ }^{\circ} \mathrm{C}$ for $30 \mathrm{~min}$; homogenized at $40 \mathrm{oC}$ for $30 \mathrm{~s}$ followed by pasteurization) were studied during storage for six months in a freezer at -18 oC. Large variations were observed in the concentrations of polyunsaturated fatty acids, particularly of docosahexaenoic acid, with a reduction of almost $50 \%$ of its total. Palmitic and stearic acid contents also changed according to the conditions of processing and storage. Correlations between the decrease of long fatty acid chains and the increase of medium and short chains were verified. Thus, we observe that operational conditions of processing and storing change human milk lipid profile, with some nutritional losses.

\section{INTRODUCTION}

Lipids are the components present in human milk that provide the greatest energy for babies and fatty acids, essential for the newborn's development and proper functioning's organism. [1] The composition of human milk lipids is a majority in triacylglycerols (98\%), containing phospholipids $(0.8 \%)$, cholesterol $(0.5 \%)$, and other 
compounds. [2] Among the fatty acids present in human milk, which are part of the newborn's cognitive system development, we can find the arachidonic (ARA) and docosahexaenoic (DHA) acids. [3] Palmitic acid (C16:0) is a fatty acid located in the triacylglycerol's sn-2 position and acts in the neonate's bone development, helping to absorb other fatty acids and calcium. [4] Thus, such acid plays an essential role in newborn development.

Human milk is the complete food for newborns, being so important that in addition to its primary function, nourishing, it has become an aid in treating preterm neonates hospitalized with diseases such as necrotizing enterocolitis. [1], [2] Since many babies in the Neonatal Intensive Care Unit (NICU) can often not suck the milk, an option for their nutrition is the use of expressed donor human milk. [5] After being collected, pasteurized, and frozen for later use, such milk can be stored for up to 6 months in Human Milk Banks (HMB). Even under freezing conditions, lipid oxidation can occur during food storage, thus altering the food's fatty acid profile. [6] Lipid oxidation occurs in unsaturated fatty acids, such as linoleic, oleic, and linolenic acids, due to the presence of their double bond. [8], [9]

Hence, the knowledge of changes in human milk's lipid profile due to its processing and storage conditions is essential and provides data on lipids' nutritional content when subjected to pasteurization, homogenization, and packing. However, no reports on this specific subject are presented in the literature as far as we know. Therefore, this work aims to evaluate the changes in the fatty acid profile of non-conform pooled human milk expressed in the human milk bank when subjected to processing and frozen storage for up to 180 days.

\section{MATERIALS AND METHODS}

\section{Ethics Statement}

The study was approved by the ethics committee of the Universidade Federal de Viçosa (reference number: 66/2018).

\section{Reagent/Solvent}

Hexane (HPLC grade, Sigma Aldrich, San Luis, Missouri, USA), Chloroform (HPLC grade, VETEC Quimica Fina, Duque de Caxias, Rio de Janeiro, Brasil), Methil Alcohol (HPLC grade, VETEC Quimica Fina, Duque de Caxias, Rio de Janeiro, Brasil), Sodium sulfate anhydrous PA (VETEC Quimica Fina, Duque de Caxias, Rio de Janeiro, Brasil), Sodium chloride PA (VETEC Quimica Fina, Duque de Caxias, Rio de Janeiro, Brasil), sodium lauryl sulfate broth (MQ300, MERCK, Darmstadt, Germany) and mix (Supelco® 37 Component FAME Mix, Sigma Aldrich, San Luis, Missouri, USA).

\section{Sample}

Pooled and expressed donor human milk used in our experiments came from the Human Milk Bank (HMB) of the Hospital São Sebastião (HSS) in Viçosa city (MG, Brazil) and would be discarded due to the presence of hair or skin found in the routine analyses. Such human milk was at appropriate microbiological conditions. Thus, it was considered suitable to carry out our experiments. All milk donated to HMB-HSS goes through sensory and physicochemical analyses previous to any treatment. [9] All the material was in glass bottles, according to Brazilian regulation. [10]

Nine bottles of expressed, donated, and pooled human milk at the mature lactation phase were transported to the laboratory under refrigeration. Each bottle's content was filtered (Whatman 1-125 mm qualitative paper, $45 \mu \mathrm{m}$ ) to dirtiness removal and was divided into three samples. Two of these three samples were processed, one of them at the pasteurized conditions and another at homogenized conditions before pasteurization. Human milk was then stored as raw human milk (RHM) - L1, pasteurized human milk (PHM) - L2, and homogenized/pasteurized human milk (HPHM) - L3. All milk samples were characterized based on fatty acid content during 180 days of storage, at intervals of 30 days. The zero time was represented by the milk collection day. All analyzes were performed in triplicate to reduce the experimental error.

\section{Physical-chemical analysis}

The human milk quality was evaluated through the Dornic acidity, physico-chemical analyses, [9] dry extract by gravimetry, and lipids content by Bligh \& Dyer (1959). [11] 


\section{Microbiological analysis}

Human milk was characterized by microbiological analysis to ensure safety. The most probable number (MNP) methodology with sodium lauryl sulfate broth was used to determine the viable numbers of human milk bacteria. [12]

\section{Pasteurization}

Raw human milk was pasteurized to eliminate the contaminating microorganisms by keeping the milk in a thermostatically-controlled water bath (Tecnal, TE-184, Brasil) at $62.5^{\circ} \mathrm{C}$ for $30 \mathrm{~min}$.

\section{Homogenization}

Raw human milk human at $40{ }^{\circ} \mathrm{C}$ was homogenized through sonication in an ultrasonic sonicator (Sonics, VCX750, Newtown, Connecticut, EUA) using a $13 \mathrm{~mm}$ probe, $20 \mathrm{kHz}$ of frequency, and $75 \%$ of intensity for $30 \mathrm{~s}$. Thus, homogenized/pasteurized human milk (HPHM) was obtained through the homogenization of raw milk, followed by pasteurization.

\section{Lipid extraction}

The lipid extraction methodology was adapted from Bligh \& Dyer (1959). [11] Milk was thawed to $40{ }^{\circ} \mathrm{C}$ in a thermostatic bath (Tecnal, TE-184, Brazil), and a mass of $0.5 \mathrm{~g}$ was weighed on an analytical balance (Shimadzu, AY220, Japan). The volume of $3 \mathrm{~mL}$ of a methanol: chloroform (2:1) mixture was added to the lipid extraction system. The mixture was kept under agitation on a shaking table (Tecnal, TE-053, Brazil) for $30 \mathrm{~min}$., and $1 \mathrm{~mL}$ of chloroform and $1.8 \mathrm{~mL}$ of a $\mathrm{NaCl}$ aqueous solution $(0.9 \mathrm{~g} / \mathrm{mL})$ were added. After the three phases splitting, the bottom $(\sim 2 \mathrm{~mL})$ was pipetted and dried $\left(45^{\circ} \mathrm{C}\right)$ in a dry bath (Labnet, D1200-230V, USA). The lipid masses were determined by gravimetry. The results revealed an average of $15 \mathrm{mg}$ of lipids/sample. The upper and intermediate phases were discarded in appropriate bottles.

\section{Derivatization}

Fat Acids Methil Esters (FAMEs) were prepared by derivatization of lipids extracted from human milk. The dry mass of extracted lipid ( $\sim 15 \mathrm{mg})$ was added of $1 \mathrm{mg}$ of standard C11 and $2 \mathrm{~mL}$ of $2 \%$ sulfuric acid in methanol. The mixture was heated in a dry bath under stirring (Labnet, D1200-230V, USA) at $90{ }^{\circ} \mathrm{C}$ and 90 min, according to an adaptation from Martínez et al. (2012). [13] Hexane (2 mL) and deionized water (1 mL) were added to the system that was vortexed (Phoenix Luferco, AP-56, Brazil) for 1 min to promote the extraction of FAMEs. After phase separation, the upper phase $(1 \mathrm{~mL})$ was transferred to a flask (Eppendorf, Germany) containing $0.05 \mathrm{~g}$ of anhydrous sodium sulfate. The mixture was centrifugated (2800 rcf, 15 min.) (Eppendorf, Germany). A volume of $500 \mu \mathrm{L}$ of supernatant was removed and added to the appropriate vial with $500 \mu \mathrm{L}$ of hexane. FAMEs content was quantified by gas chromatography analysis (GC-FID Shimadzu, 2010, Japan), using a $100 \mathrm{~m}$ x $0.25 \mathrm{~mm}$ capillary column (SP2560, Sigma Aldrich, USA).

The fatty acids were identified through the retention times of the sample FAMEs compared to the retention times of the FAME standard calibration mix (Supelco® 37 Component FAME Mix, Sigma Aldrich, USA). Three repetitions were performed for the analysis of each sample.

\section{Data analysis}

The observed data were statistically analyzed using a completely randomized design in the R program version 3.3.3. [14] At 5\% of significance: (1) the Scott-Knott test was used to evaluate the averages; (2) the Shapiro-Wilk test, the residual normality; (3) the Bartlett test, the variance homogeneity; and (4) the Pearson's correlation method, the correlation among the fatty acids.

\section{RESULTS AND DISCUSSION}

The variations of fatty acid concentrations of human milk were evaluated to determine the changes in the fatty acid profile: (1) for expressed, donated, and pooled milk; (2) at three processing conditions, of raw milk, pasteurized, and homogenized/pasteurized milk; and (3) every 30 days during 180 days of storage. T0 stands for the day of milk 
collection at HSS, T1 for 30 days of storage after milk collection, and T2 for 60 days of storage until T6. T6 represents 180 days of human milk storage.

\section{Raw expressed, donated, and pooled human milk}

For raw expressed, donated, and pooled human milk (EHM), as shown in Fig. 1, we observed (i) a predominance of saturated fatty acids (47.24\%), followed by monounsaturated fatty acids (MUFA's) (32.44\%) and polyunsaturated fatty acids (PUFA's) (17.45\%); (ii) changes in the average values of fatty acid concentrations; (iii) a constant decay in the contents of Polyunsaturated Fatty Acids (PUFAs) until time T4 With subsequent increase; (iv) several fluctuations in the levels of Monounsaturated Fatty Acids (MUFAs); $(v)$ maintenance of saturated fatty acid concentrations at times T0 and T1; (vi) decrease of saturated fatty acid concentrations at times T2 to T6; (vii) intense change of PUFA's contents (docosahexaenoic [DHA], arachidonic [ARA], eicosapentaenoic [EPA], linoleic [LA], alphalinolenic [ALA], and oleic acids) at the beginning of the storage; (viii) a moderate change of the saturated fatty acid contents at the beginning of the storage; (ix) a high reduction of the fatty acid saturated values at T3-T4 and T5-T6 .
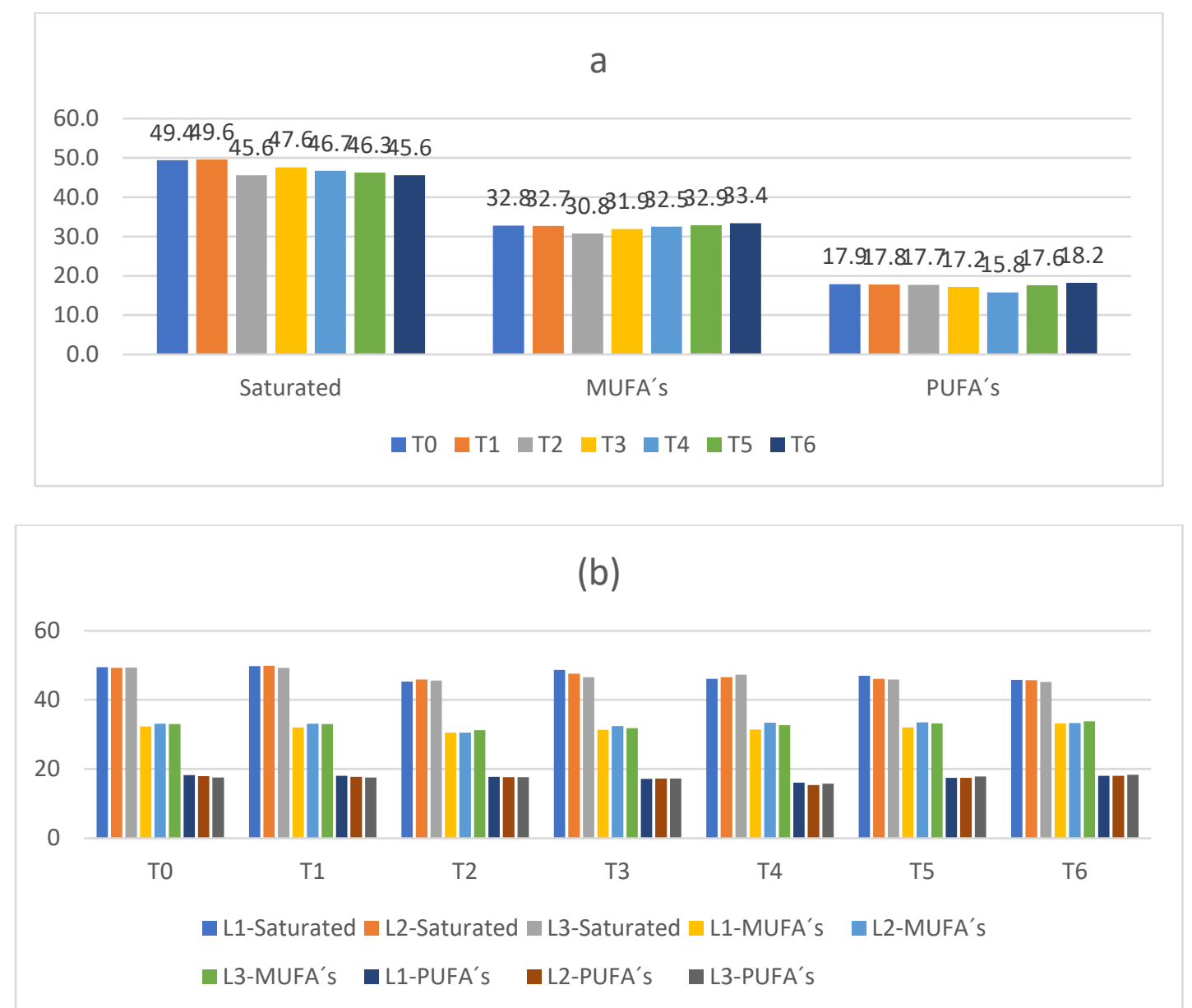

Figure 1 (a) and (b): Saturated fatty acids, MUFAs, and PUFAs during storage time. (L1): Raw human milk. (L2): Pasteurized human milk. (L3): Pasteurized/homogenized human milk Storage times: T0 to T6.

\section{Pasteurized and homogenized/pasteurized human milk}

As shown in Table 1, human milk presented after processing higher contents of long-chain fatty acids, such as EPA, ARA, ALA, oleic acid, and palmitic acid, than raw milk. It should be noted that the composition of DHA and linoleic acid in raw milk was higher than that after processing ( $\sim 10 \%$ of DHA, $\sim 4 \%$ of linoleic acid). The milk processing conditions diminished the concentrations of long-chain fatty acids due to their conversion into shortchain fatty acids. Such behavior was already reported for the enzymatic conversion of long-chain to short-chain fatty acids. [15] Polyunsaturated fatty acids presented their highest levels at the beginning of storage, with a reduction in their percentage in the following months, except AL and ARA. 
During the $\beta$-oxidation of long-chain fatty acids, short-chain fatty acids occur, which can be later oxidized. Human milk has antioxidant compounds in its constitution, which can provide an overall antioxidant capacity and reduce and paralyze oxidation reactions of long-chain fatty acids, with an increase in short-chain concentration fatty acids have. [16], [17]

Table 1: Proportion of human milk fatty acids at different process conditions and storage times.

\begin{tabular}{|l|c|c|c|c|c|c|c|}
\hline & C16:0 & C18:1n9c & C18:2n6c & C18:3n3 & C20:4n6 & C20:5n3 & C22:6n3 \\
\hline L1 T0 & $23.081 b B$ & $28.712 \mathrm{cE}$ & $15.702 \mathrm{aB}$ & $1.739 \mathrm{cB}$ & $0.0437 \mathrm{cD}$ & $0.0707 \mathrm{cA}$ & $0.695 \mathrm{aA}$ \\
\hline L2 T0 & $22.727 \mathrm{cB}$ & $29.816 \mathrm{aE}$ & $15.296 \mathrm{bC}$ & $1.894 \mathrm{aA}$ & $0.0491 \mathrm{aD}$ & $0.0748 \mathrm{bA}$ & $0.631 \mathrm{bA}$ \\
\hline L3 T0 & $23.091 \mathrm{aA}$ & $29.504 \mathrm{bE}$ & $14.958 \mathrm{cE}$ & $1.827 \mathrm{bB}$ & $0.0471 \mathrm{bE}$ & $0.0791 \mathrm{aA}$ & $0.625 \mathrm{cA}$ \\
\hline L1 T1 & $23.014 \mathrm{bC}$ & $28.718 \mathrm{cD}$ & $15.477 \mathrm{aC}$ & $1.732 \mathrm{cC}$ & $0.0401 \mathrm{bF}$ & $0.0700 \mathrm{cB}$ & $0.693 \mathrm{aA}$ \\
\hline L2 T1 & $22.973 \mathrm{cA}$ & $29.841 \mathrm{aD}$ & $15.252 \mathrm{bD}$ & $1.802 \mathrm{bB}$ & $0.0403 \mathrm{bG}$ & $0.0721 \mathrm{bB}$ & $0.633 \mathrm{bA}$ \\
\hline L3 T1 & $23.024 \mathrm{aB}$ & $29.559 \mathrm{bD}$ & $14.941 \mathrm{cF}$ & $1.823 \mathrm{aB}$ & $0.0474 \mathrm{aDE}$ & $0.0791 \mathrm{aA}$ & $0.626 \mathrm{cA}$ \\
\hline L1T2 & $20.938 \mathrm{cG}$ & $27.533 \mathrm{cG}$ & $15.371 \mathrm{aD}$ & $1.765 \mathrm{bA}$ & $0.0512 \mathrm{cC}$ & $0.0162 \mathrm{bE}$ & $0.507 \mathrm{aB}$ \\
\hline L2 T2 & $21.456 \mathrm{aG}$ & $27.857 \mathrm{bG}$ & $15.143 \mathrm{cE}$ & $1.897 \mathrm{aA}$ & $0.0583 \mathrm{aB}$ & $0.0159 \mathrm{cE}$ & $0.490 \mathrm{bB}$ \\
\hline L3 T2 & $21.353 \mathrm{bG}$ & $28.695 \mathrm{aG}$ & $15.345 \mathrm{bC}$ & $1.730 \mathrm{cD}$ & $0.0537 \mathrm{bB}$ & $0.0173 \mathrm{aE}$ & $0.490 \mathrm{bB}$ \\
\hline L1 T3 & $23.163 \mathrm{aA}$ & $28.506 \mathrm{cF}$ & $15.037 \mathrm{bF}$ & $1.533 \mathrm{cF}$ & $0.0516 \mathrm{aC}$ & $0.0128 \mathrm{bF}$ & $0.499 \mathrm{aC}$ \\
\hline L2 T3 & $22.558 \mathrm{bE}$ & $29.514 \mathrm{aF}$ & $15.039 \mathrm{bF}$ & $1.695 \mathrm{aD}$ & $0.0442 \mathrm{cE}$ & $0.0118 \mathrm{cG}$ & $0.487 \mathrm{bC}$ \\
\hline L3 T3 & $21.940 \mathrm{cF}$ & $28.999 \mathrm{bF}$ & $15.060 \mathrm{aD}$ & $1.637 \mathrm{bE}$ & $0.0476 \mathrm{bD}$ & $0.0139 \mathrm{aF}$ & $0.462 \mathrm{cC}$ \\
\hline L1 T4 & $22.771 \mathrm{aD}$ & $28.969 \mathrm{cC}$ & $14.152 \mathrm{aG}$ & $1.381 \mathrm{aG}$ & $0.0428 \mathrm{bE}$ & $0.0125 \mathrm{cF}$ & $0.492 \mathrm{aD}$ \\
\hline L2 T4 & $22.636 \mathrm{bD}$ & $30.533 \mathrm{aB}$ & $13.496 \mathrm{cG}$ & $1.271 \mathrm{cF}$ & $0.0418 \mathrm{cF}$ & $0.0608 \mathrm{bC}$ & $0.481 \mathrm{bD}$ \\
\hline L3 T4 & $22.565 \mathrm{cC}$ & $29.947 \mathrm{bC}$ & $13.853 \mathrm{bG}$ & $1.366 \mathrm{bF}$ & $0.0484 \mathrm{aC}$ & $0.0729 \mathrm{aB}$ & $0.456 \mathrm{cD}$ \\
\hline L1 T5 & $22.268 \mathrm{bE}$ & $29.250 \mathrm{cB}$ & $15.262 \mathrm{cE}$ & $1.687 \mathrm{bE}$ & $0.0657 \mathrm{aA}$ & $0.0190 \mathrm{bD}$ & $0.377 \mathrm{aE}$ \\
\hline L2 T5 & $22.664 \mathrm{aC}$ & $30.730 \mathrm{aA}$ & $15.444 \mathrm{bB}$ & $1.605 \mathrm{cE}$ & $0.0557 \mathrm{cC}$ & $0.0147 \mathrm{cF}$ & $0.303 \mathrm{cF}$ \\
\hline L3 T5 & $22.225 \mathrm{cE}$ & $30.406 \mathrm{bB}$ & $15.617 \mathrm{aB}$ & $1.779 \mathrm{aC}$ & $0.0603 \mathrm{bA}$ & $0.0202 \mathrm{aC}$ & $0.354 \mathrm{bE}$ \\
\hline L1 T6 & $22.170 \mathrm{cF}$ & $30.458 \mathrm{cA}$ & $15.915 \mathrm{bA}$ & $1.692 \mathrm{cD}$ & $0.0604 \mathrm{bB}$ & $0.0205 \mathrm{aC}$ & $0.356 \mathrm{aF}$ \\
\hline L2 T6 & $22.537 \mathrm{aF}$ & $30.506 \mathrm{bC}$ & $15.866 \mathrm{cA}$ & $1.736 \mathrm{bC}$ & $0.0612 \mathrm{aA}$ & $0.0202 \mathrm{bD}$ & $0.313 \mathrm{cE}$ \\
\hline L3 T6 & $22.301 \mathrm{bD}$ & $30.978 \mathrm{aA}$ & $16.120 \mathrm{aA}$ & $1.863 \mathrm{aA}$ & $0.0604 \mathrm{bA}$ & $0.0183 \mathrm{cD}$ & $0.326 \mathrm{bF}$ \\
\hline
\end{tabular}

L1: Raw human milk; L2: Pasteurized human milk; L3: Pasteurized/homogenized human milk. Storage times: 0 to 180 days (T0, T1, T2, T3, T4, T5, T6). Uppercase letters after data show the statistical variations between storage time and lowercase letters after data show the statistical variations between type of processing ( $p \leq 0.05$ by the Scott-Knott test).

As seen in Fig. 2, an increase in the content of short-chain fatty acids ( 6 and 8 carbons) can be seen in the first 60 days of storage, reducing their levels in the last 90 days. The C6:0 content showed a remarkable increase, and the C8:0 composition a great variation during storage.

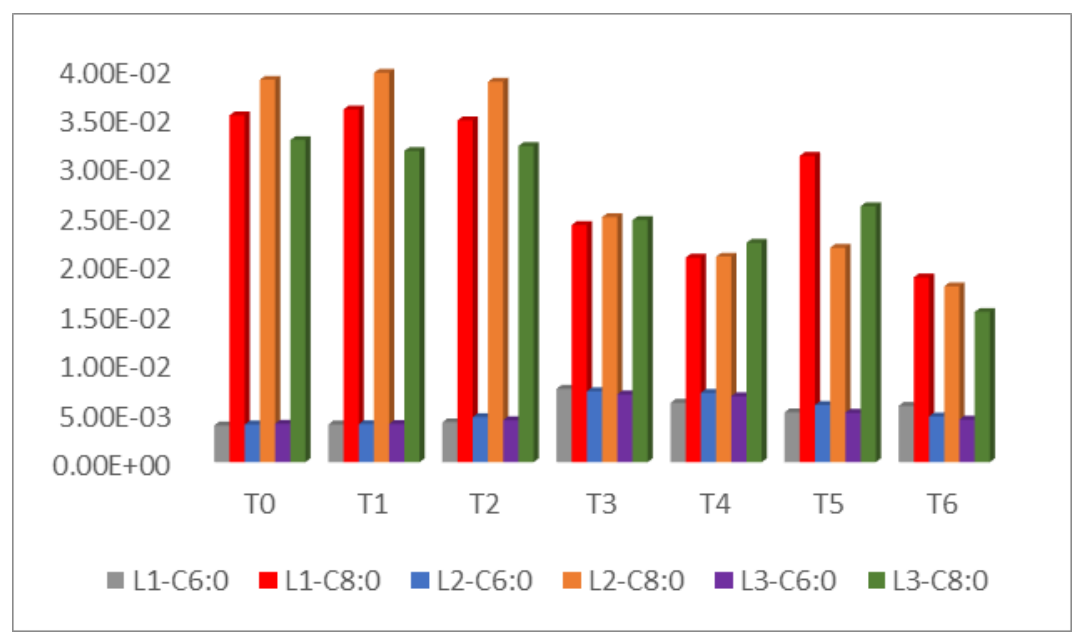

Figure 2: Variation in C6:0 and C8:0 levels during 180 days of storage. L1: Raw human milk; L2: Pasteurized human milk; L3: Pasteurized/homogenized human milk. Storage times: 0 to 180 days (T0, T1, T2, T3, T4, T5, T6). 
Fig. 3 (a) and (b) shows (i) the decrease of unsaturated fatty acid contents, such as oleic acid and EPA, in the first 30 days of storage and the increase from 90 days; (ii) the proportion change of some fatty acids, like ALA, LA, ARA, palmitic and stearic, throughout storage; (iii) the abrupt reduction of DHA composition in the first 30 days of storage, followed by a smooth decrease until the end of storage.

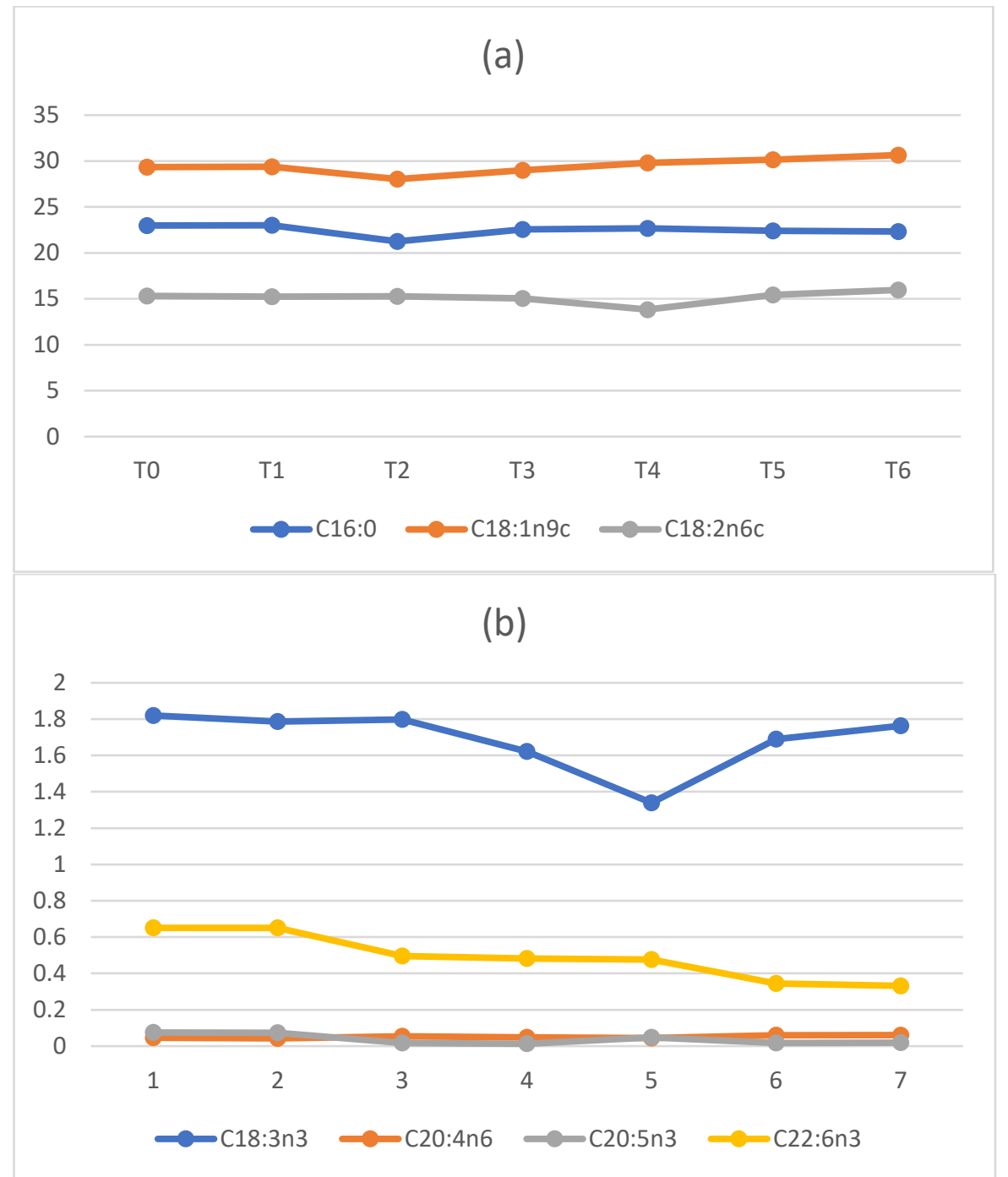

Figure 3 (a) and (b): Variations of fatty acid's compositions during 180 days of storage. Storage times: 0 to 180 days (T0, T1, T2, T3, T4, T5, T6).

\section{Correlations}

The evaluation of the fatty acid composition changes clarifies that some of such variations can be correlated. Regarding the processing, DHA content showed a strong negative correlation with ARA (-0.89), EPA (-0.89), linolenic $(-0.86)$, oleic $(-0.93)$, lauric $(-0.99)$, and caproic $(-0.91)$ acids. This behavior suggests decreased DHA concentrations and the increase of those acid concentrations due to processing conditions. A reduction in DHA content was verified in the human milk analyzed. On the other hand, linoleic, arachidic, and myristic acids showed positive correlations with DHA (0.92, 0.99, and 0.77 respectively), meaning an increase in DHA concentration with the rise of such acids' contents.

EPA also showed a strong negative correlation with arachidic $(-0.90)$, linoleic $(-0.99)$, cis-10-heptadecanoic $(-$ $0.95)$ and myristic (-0.97) acids, and a strong positive correlation with caproic (0.99), lauric (0.91), and tridecanoic (0.93) acids.

Correlations between long-chain fatty acids, such as DHA, EPA, and ARA, were verified between themselves and their precursors due to the influence of the processing type on fatty acid compositions. Meantime, most correlations 
occurred among them and fatty acids of medium and low molecular weight $(\leq \mathrm{C} 14)$. However, changes in fatty acid compositions during storage were not correlated with their precursors.

An increase in the medium- and short-chain contents and a long-chain diminution were noted for the most correlations among the fatty acids. Thus, the concentration of fatty acids of greater molecular weight decreased through their oxidative degradation and reduced the formation of medium and short-chain fatty acids.

Human milk lipids act in developing newborns, such as weight gain, responsible for using up to $50 \%$ of the energy provided by human milk; developing cognitive, visual, and immune newborn systems; and has a regulatory role in the body, many others. Some fatty acids that make up these lipids play indispensable roles in forming and functioning a baby's body, such as DHA, ARA, and EPA, which are part of the nervous and visual system. The palmitic acid helps to absorb other fatty acids and calcium, leading it to develop the bone and digestive system. [18], [19], [20]

The literature reported changes in human milk's fatty acid profile due to age, lactation period, and mother's diet. [21] However, no information was found on the lipid profile changes after milking, processing, and storage of human milk, as far as we know.

Human milk is a bioactive material containing endogenous lipases. Thus, appropriate storage conditions are necessary to avoid these enzymes' action [22] and changes in the lipid profile. Besides the enzymatic action, human milk composition can be altered by oxidation due to exposure to oxygen and moisture. Oxidation reactions are stimulated by temperature increase and some physical treatments, leading to an increase in the exposure of lipids. [23]

PUFAs have pre-availability to oxidation due to the double bond's fragility in their chains, showing changes in its concentrations after undergoing heat treatment. However, oxidative degradation also occurs in systems containing saturated fatty acids. [24], [25] This behavior was verified by us for the fatty acids of human milk at each analyzed process condition and milk storage time.

During oxidation, polyunsaturated fatty acids were hydrolyzed to form smaller fatty acids. [26] This occurrence is justified by the observed negative correlation between long-chain fatty acids and those of short-chain.

Each fatty acid acts in important functions in the baby's body. DHA and ARA participate in the development of the cognitive and visual systems. The accumulation of DHA in the lipid membrane of the central nervous system was observed in the first months of life. [27] Palmitic acid aids in the absorption of calcium and other fatty acids, playing a role in forming the newborn's bones and the digestive system. [28]

Changes in the lipid profiles can lead to variations in their nutritional qualities. [29] Thus, according to each neonate's needs, the knowledge of such variations may help a better prescription of the type of processed human milk linked to the storage times if direct breastfeeding could not be used. The decrease of fatty acid levels causes a nutrient loss for newborns, especially the preterm. Thus, it is essential to observe each infant's individual needs. [30]

The changes in the fatty acid contents found in this work are substantial, but their averages are in the range reported in the literature for raw human milk in several countries worldwide, such as Australia and Cambodia, South Korea, China, and Chile. [1], [31], [32] Thus, human milk remains an excellent nutritional source of fatty acids, even after processing and storage.

\section{CONCLUSION}

Human milk's fatty acid profile was affected by the operational conditions used in pasteurization and homogenization, and also the storage time for up to six months. The literature recognizes fresh and healthy mothers' milk provided by direct breastfeeding as the best type of milk for a newborn's complete nutrition. Nevertheless, even after processing and storage, human milk remains an excellent nutritional source of fatty acids because its lipids' high nutritional quality is maintained. Changes in the lipid compositions can promote variations in their nutritional qualities. Thus, information on such changes may help develop formulae following each neonate's lipids needs if breastfeeding could not be adopted. Hence, the nutritional relevance of processed human milk makes its use viable.

\section{SOURCES OF FUNDING}

This research received no specific grant from any funding agency in the public, commercial, or not-for-profit sectors.

International Journal of Research -GRANTHAALAYAH 
Otávio A. S. Ribeiro, Kely P. Correa, Mauricio O. Leite, Marcio A. Martins, and Jane S. R. Coimbra

\section{CONFLICT OF INTEREST}

The author have declared that no competing interests exist.

\section{ACKNOWLEDGMENT}

The authors are grateful to the Human Milk Research Group of the Instituto Fernandes Figueiras/Fundação Oswaldo Cruz (IFF/FIOCRUZ) and the Laboratory of Operations and Process (LOP/UFV/DTA) for the academic support to develop the present work. The authors thank the financial support of the Coordenação de Aperfeiçoamento de Pessoal de Nível Superior (CAPES), Conselho Nacional de Desenvolvimento Científico e Tecnológico (CNPq), Fundação de Amparo à Pesquisa do Estado de Minas Gerais (FAPEMIG), and PETROBRAS.

\section{REFERENCES}

[1] R. Yuhas, K. Pramuk, and E. L. Lien, "Human Milk Fatty Acid Composition from Nine Countries Varies Most in DHA," Lipids, vol. 41, no. 9, pp. 2-4, 2006.

[2] J. Kim and J. Friel, "Lipids and human milk," Lipid Technol., vol. 24, no. 5, pp. 103-105, 2012, doi: 10.1002/lite.201200190.

[3] B. A. Juber, K. H. Jackson, K. B. Johnson, W. S. Harris, and M. L. Baack, "Breast milk DHA levels may increase after informing women: A community-based cohort study from South Dakota USA," Int. Breastfeed. J., vol. 12, no. 1, pp. 1-9, 2017, doi: 10.1186/s13006-016-0099-0.

[4] C. Sun, W. Wei, H. Su, X. Zou, and X. Wang, "Evaluation of sn -2 fatty acid composition in commercial infant formulas on the Chinese market : A comparative study based on fat source and stage," Food Chem., vol. 242, no. August 2017, pp. 29-36, 2018.

[5] M. Quigley, N. D. Embleton, and W. McGuire, "Formula versus maternal breast milk for feeding preterm or low birth weight infants," Cochrane Database Syst. Rev., no. 6, 2018, doi: 10.1002/14651858.CD002972.pub3.

[6] L. R. B. Mariutti, G. C. Nogueira, and N. Bragagnolo, "Lipid and Cholesterol Oxidation in Chicken Meat Are Inhibited by Sage but Not by Garlic,” J. Food Sci., vol. 76, no. 6, pp. C909-C915, Aug. 2011, doi: 10.1111/j.17503841.2011.02274.x.

[7] T. Nah, S. H. Kessler, K. E. Daumit, J. H. Kroll, S. R. Leone Abe, and K. R. Wilson, "OH-initiated oxidation of submicron unsaturated fatty acid particles," Phys. Chem. Chem. Phys., vol. 15, pp. 18649-18663, 2013, doi: $10.1039 / \mathrm{c} 3 \mathrm{cp} 52655 \mathrm{k}$.

[8] S. A. Vieira, G. Zhang, and E. A. Decker, "Biological Implications of Lipid Oxidation Products," J. Am. Oil Chem. Soc., vol. 94, no. 3, pp. 339-351, 2017, doi: 10.1007/s11746-017-2958-2.

[9] J. A. G. de Almeida, V. Guimarães, and F. R. Novak, "Seleção e Classificação do Leite Humano Ordenhado Cru," Centro de Referência Nacional para Bancos de Leite Humano - Instituto Fernandes Figueira / Fundação Oswaldo Cruz / Ministério $\quad$ da $\quad$ Saúde, 2011. https://rblh.fiocruz.br/sites/rblh.fiocruz.br/files/usuario/79/nt_23.11_selec._classif_lhocru.pdf (accessed Sep. 21, 2020).

[10] J. A. G. de Almeida, F. R. Novak, and V. Guimarães, “Embalagem para o Leite Humano Ordenhado," Cent. Ref. Nac. para Bancos Leite Hum. - Inst. Fernandes Figueira / Fundação Oswaldo Cruz / Ministério da Saúde, pp. 3-6, 2011.

[11] E. G. BLIGH and W. J. DYER, “A RAPID METHOD OF TOTAL LIPID EXTRATION AND PURIFICATION,” Can. J. Biochem. Physiol., vol. 37, pp. 911-917, 1959, doi: dx.doi.org/10.1139/cjz-2013-0052.

[12] M. P. Silva, D. R. Cavalli, and T. C. R. M. Oliveira, "Avaliação do padrão coliformes a 45oC e comparação da eficiência das técnicas dos tubos múltiplos e Petrifilm EC na detecção de coliformes totais e Escherichia coli em alimentos," Ciência e Tecnol. Aliment., vol. 26, no. 2, pp. 352-359, 2006, doi: 10.1590/s010120612006000200018.

[13] B. Martínez et al., "Development of a simple method for the quantitative determination of fatty acids in milk with special emphasis on long-chain fatty acids," CyTA J. Food, vol. 6337, 2012, doi: 10.1080/19476337.2010.538860.

[14] "R: The R Project for Statistical Computing.” https://www.r-project.org/ (accessed Mar. 31, 2019). 
Fatty Acid Profile of Non-Conforming Pooled Human Milk as Affected by The Processing and Storage Conditions

[15] F. DAVIDOFF and E. D. KORN, "The Conversion of Long Chain Saturated Fatty Acids To Their Alpha," J. Biol. Chem., vol. 239, no. 8, pp. 2496-2506, 1964.

[16] C. Leber, J. W. Choi, B. Polson, and N. A. Da Silva, "Disrupted short chain specific $\beta$-oxidation and improved synthase expression increase synthesis of short chain fatty acids in Saccharomyces cerevisiae," Biotechnol. Bioeng., vol. 113, no. 4, pp. 895-900, 2016, doi: 10.1002/bit.25839.

[17] S. M. B. Hashemi et al., "Fermentation of sarshir (kaymak) by lactic acid bacteria: antibacterial activity, antioxidant properties, lipid and protein oxidation and fatty acid profile," J. Sci. Food Agric., vol. 97, no. 13, pp. 4595-4603, 2017, doi: 10.1002/jsfa.8329.

[18] F. Davidoff and E. D. Korn, "THE CONVERSION OF LONG CHAIN SATURATED FATTY ACIDS TO THEIR ALPHA, BETA-UNSATURATED, BETA, GAMMA-UNSATURATED, AND BETA-HYDROXY DERIVATIVES BY ENZYMES FROM THE CELLULAR SLIME MOLD, DICTYOSTELIUM DISCOIDEUM," J. Biol. Chem., vol. 239, p. 2496-2506, 1964, [Online]. Available: http://europepmc.org/abstract/MED/14235527.

[19] V. Grote et al., "Breast milk composition and infant nutrient intakes during the first 12 months of life," Eur. J. Clin. Nutr., vol. 70, no. 2, pp. 250-256, 2016, doi: 10.1038/ejcn.2015.162.

[20] S. M. Innis, "Dietary Triacylglycerol Structure and Its Role in Infant Nutrition," Adv. Nutr., vol. 2, no. 3, pp. 275283, 2011, doi: 10.3945/an.111.000448.

[21] D. K. Dror and L. H. Allen, "Overview of Nutrients in Human Milk," Advantages Nutr., vol. 9, pp. 278S-294S, 2018.

[22] A. D. George, M. C. L. Gay, R. D. Trengove, and D. T. Geddes, "Human Milk Lipidomics : Current Techniques and Methodologies," Nutrients, vol. 10, 2018, doi: 10.3390/nu10091169.

[23] E. Koh and J. Surh, "Food types and frying frequency affect the lipid oxidation of deep frying oil for the preparation of school meals in Korea," Food Chem., vol. 174, pp. 467-472, 2015, doi: 10.1016/j.foodchem.2014.11.087.

[24] W. P. Batiston, S. A. Maruyama, S. T. M. Gomes, J. V. Visentainer, N. E. De Souza, and M. Matsushita, "Absolute quantification of fatty acid and proximate composition of cow and goat powdered milks," J. Braz. Chem. Soc., vol. 23, no. 10, pp. 1907-1914, 2012, doi: 10.1590/S0103-50532012005000061.

[25] T. S. Kim, J. Yeo, J. Y. Kim, M. J. Kim, and J. Lee, "Determination of the degree of oxidation in highly-oxidised lipids using profile changes of fatty acids," Food Chem., vol. 138, no. 2-3, pp. 1792-1799, 2013, doi: 10.1016/j.foodchem.2012.11.119.

[26] M. Sabetian, S. T. Delshad, S. Moini, H. R. Islami, R. Beglaryan, and A. Motalebi, "Identification and changes in fatty acid profile of rainbow trout (Oncorhynchus mykiss) fillet during frozen storage $\left(-18^{\circ} \mathrm{C}\right)$, , J. Aquat. Food Prod. Technol., vol. 23, no. 4, pp. 321-332, 2014, doi: 10.1080/10498850.2012.717592.

[27] A. Lapillonne, S. Groh-Wargo, C. H. Lozano Gonzalez, and R. Uauy, "Lipid needs of preterm infants: Updated recommendations,” J. Pediatr., vol. 162, no. 3 SUPPL., pp. 37-47, 2013, doi: 10.1016/j.jpeds.2012.11.052.

[28] V. Petit, L. Sandoz, and C. L. Garcia-Rodenas, "Importance of the regiospecific distribution of long-chain saturated fatty acids on gut comfort, fat and calcium absorption in infants," Prostaglandins Leukotrienes and Essential Fatty Acids, vol. 121. pp. 40-51, 2017, doi: 10.1016/j.plefa.2017.05.007.

[29] K. Liu, Y. Liu, and F. Chen, "Effect of storage temperature on lipid oxidation and changes in nutrient contents in peanuts," Food Sci. Nutr., vol. 7, no. 7, pp. 2280-2290, 2019, doi: 10.1002/fsn3.1069.

[30] Y.-B. He, H.-W. Ren, Y.-T. Cao, H.-J. Li, Z. Zhang, and N. Liu, "Comparing the composition and trend of fatty acid in human milk with bovine milk and infant formula in northeast region of China," CyTA - Journal of Food, vol. 14, no. 4. pp. 632-638, 2016, doi: 10.1080/19476337.2016.1188858.

[31] C. Gao et al., "Comparison of Human Milk Fatty Acid Composition of Women from Cambodia and Australia," J. Hum. Lact., vol. 34, no. 3, pp. 585-591, 2018, doi: 10.1177/0890334418772279.

[32] H. Kim, S. Kang, B. M. Jung, H. Yi, J. A. Jung, and N. Chang, "Breast milk fatty acid composition and fatty acid intake of lactating mothers in South Korea," Br. J. Nutr., vol. 117, no. 4, pp. 556-561, 2017, doi: $10.1017 /$ S0007114517000253. 